\title{
PROJETO DE ALFABETIZAÇÃO DE JOVENS E ADULTOS PELA EDUCAÇÃO EM SAÚDE: 25 A̧NOS DE HISTÓRIA PARA CONTAR
}

\section{LITERACY PROJECT FOR YOUTH AND ADULTS BY HEALTH EDUCATION: 25 YEARS OF HISTORY TO TELL}

\author{
Beatriz Preto Almirall Seliger ${ }^{1}$ \\ Stefanie Cristina Pires Amancio ${ }^{2}$ \\ Natália Sayuri Komakome \\ Brito $^{3}$ \\ Amanda Sayuri Sitoo \\ Onary ${ }^{4}$ \\ Eliana Goldfarb Cyrino 5
}

\begin{abstract}
RESUMO
O presente texto tem como objetivo relatar a experiência, na alfabetização de jovens e adultos, em extensão de graduandos de diferentes cursos do campus da Unesp Botucatu. O projeto de alfabetização de jovens e adultos de Botucatu é desenvolvido há 25 anos, trabalhando, desde o início, a partir da metodologia de ensino de Paulo Freire, com foco na relação educador-educando; nas necessidades de saúde dos educandos; no aprendizado a partir de saberes compartilhados; na interação educação de adultos; na autonomia dos sujeitos e na promoção da saúde. A partir de relatos dos protagonistas, graduandos e educandos do projeto, foi possível trazer a riqueza da experiência, de suas vivências e da aprendizagem no projeto.
\end{abstract}

Palavras chave: Alfabetização de jovens e adultos. Educação de jovens e adultos. Extensão universitária. Saberes compartilhados

\footnotetext{
ABSTRACT

The present text has an objective to report the experience in extension of graduates of different courses on campus of Unesp Botucatu, in the literacy of young people and adults. The Botucatu youth and adult literacy project has been developed for 25 years, working from the beginning, based on Paulo Freire's teaching methodology, with a focus on the educator-educator relationship, on the health needs of learners, on learning to from shared knowledge, in the interaction between adult education, the

1 Estudante de graduação de medicina da Universidade Estadual Paulista Júlio de Mesquita Filho. Email: beatrizpreto94@gmail.com

${ }^{2}$ Especialização em Residência Multiprofissional em Saúde do Adulto e do Idoso pela Faculdade de Medicina de Botucatu(FMB). Email: scpamancio@gmail.com

${ }^{3}$ Estudante de graduação de medicina da Universidade Estadual Paulista Júlio de Mesquita Filho. Email: nataliakomakome@gmail.com

${ }^{4}$ Estudante de graduação de enfermagem na Universidade Estadual Paulista Júlio de Mesquita Filho. Email: usuimisaki0@gmail.com

${ }^{5}$ Doutorado em Pediatria [Botucatu] pela Universidade Estadual Paulista Júlio de Mesquita Filho, Brasil(2002).

Professora adjunta da Universidade Estadual Paulista Júlio de Mesquita Filho. Email: ecyrino@fmb.unesp.br
} 
autonomy of the subjects and in the promotion of health. From the reports of the protagonists, students and students of the project, it was possible to bring the wealth of experience, their experiences and learning in the project.

Keywords: Education of young people and adults. Extension. Literacy of young people and adults. University Shared knowledge

\section{INTRODUÇÃO}

Segundo Freire (2009) o “[...] analfabetismo não é uma 'chaga', nem uma 'erva daninha' a ser erradicada, nem tampouco uma enfermidade, mas uma das expressões concretas de uma realidade social injusta." (FREIRE apud FERRARO, 2009:7). As altas taxas de analfabetismo ainda existentes no Brasil, devem-se principalmente ao processo histórico essencialmente excludente que se desenvolveu no país desde a sua colonização. Dessa forma, para entender melhor esse processo, é preciso analisar a história da educação e escolarização no Brasil.

O processo de educação no Brasil iniciou-se no período colonial, a partir da ação dos Jesuítas: "(...) os jesuítas são considerados os principais agentes educativos do Brasil desde sua chegada em 1549 até 1759, quando foram expulsos pelas novas diretrizes da economia e da política portuguesas." (SOARES e GALVÃO, 2004, p. 29). Os Jesuítas estavam interessados em catequizar a população indígena já presente no território colonial antes da chegada dos portugueses, assim como a população escrava vinda da África posteriormente a fim de aumentar o número de fiéis católicos. Assim, o objetivo de educar essa população não estava relacionado a promover sua autonomia ou inclusão, mas se relacionava a ensinar normas de comportamentos e ofícios necessários para o funcionamento da economia colonial, estando essa educação fora da realidade social e da necessidade da população.

No século XIX, com o início do período imperial, houve uma preocupação maior em relação à institucionalização da escolarização. Com a constituição de 1824 , foi estabelecido o direito à educação primária pública para todos os cidadãos (BRASIL, 1824- Título 8, Art, 179 XXXII), correspondentes apenas aos homens livres, o que não incluía mulheres e escravos. Dessa forma, houve a exclusão de grande parte da população no processo educativo, voltado apenas para essa camada considerada cidadã. E, mesmo em relação à camada dos cidadãos, essa escolarização não foi tão efetiva, por lenta implantação dessas escolas primárias, o que não tornou possível uma ampla abrangência dessa população, marginalizando do processo principalmente as camadas menos privilegiadas. 
Nesse período, apenas em 1834, com o ato adicional, desenvolvem-se políticas nacionais, com caráter filantrópico, para a educação especificamente de jovens e adultos. No entanto, poucas medidas foram tomadas efetivamente pelas elites para providenciar educação a esses adultos não escolarizados das "camadas inferiores da sociedade". A instrução dessa população, proposta a partir do ato adicional, objetivava a sua civilização assim como a correção de sua dicção, considerada errada para as camadas superiores. Assim, na verdade, essa educação continua não centralizada nas necessidades sociais, mas sim em um desenvolvimento e "melhoria” da população e do país. (SOARES E GALVÃO, 2004)

Com a Lei Saraiva de 9 de janeiro de 1881, as pessoas analfabetas foram excluídas do direito ao voto; pois, nesse período, era difundida a ideia de que pessoas com baixa experiência escolar eram inferiores aquelas com acesso a escolarização. No entanto, a grande maioria da população não tinha acesso a alfabetização. O primeiro recenseamento nacional foi realizado em 1872, e nele, constava-se que $82,3 \%$ das pessoas com mais de cinco anos de idade eram analfabetas (IBGE, SENSO DEMOGRÁFICO 1872).

A partir da introdução do regime republicano no Brasil houve a renovação da esperança da população. Nessa nova fase brasileira, promulgou-se a constituição de 1891, com característica descentralizada e representativa, que mantinha a proibição do voto de analfabetos (BRASIL, 1891-Titulo IV, Secção I, Art. 70, §1 ${ }^{\circ}, 2^{\circ}$ ). Porém, alguns intelectuais e políticos, como José Bonifácio, eram contra a manutenção da proibição do voto de analfabetos em uma nação como o Brasil, sem oportunidades de estudo a todos e com má infraestrutura para atender a essa demanda social. (FERRARO, 2009).

Nesse período, havia uma grande discordância em relação à política educativa ideal para o Brasil. Por um lado, houve um incentivo à instrução do povo, principalmente nos discursos políticos, pois, as altas taxas de analfabetismo da população eram motivo de vergonha nacional e elucidavam a falta de desenvolvimento do país. Porém, ao mesmo tempo, muitos membros da elite eram contra a ideia da alfabetização da população; pois, com uma camada popular instruída, o controle sobre ela seria mais difícil, podendo culminar em uma certa "anarquia social".

“ Toda essa gente que, inculta e ignorante, se sujeita a vegetar, se contenta em ocupações inferiores, sabendo ler e escrever aspirará outras coisas, quererá outra situação e como não há outras profissões práticas, nem temos capacidade para criálas, desejará também ela conseguir emprego público" (CARNEIRO LEÃO, 1939, p. $165)$. 
Dessa forma, o governo republicano apesar de fazer modificação no sistema educacional nacional, essas modificações não passaram de medidas superficiais, sem modificar a estrutura do ensino básico substancialmente, mantendo-se um baixo investimento na área e uma falta de comprometimento público. (FERRARO, 2009)

Os movimentos sociais favoráveis à amplificação e à melhoria da qualidade da escolarização do país começaram a ganhar mais força a partir da década de 1920. Nessa época, iniciou-se o desenvolvimento de políticas públicas destinadas à educação de jovens e adultos tal como a Liga Brasileira contra o analfabetismo, originada do Clube militar do Rio de Janeiro em 1915.

No período do Estado Novo, a partir da revolução de 1930, a nova constituição propôs uma politica educacional mais efetiva. Nessa constituição houve 17 artigos dedicados à educação, destacando-se o art. 148, a partir do qual se estabelece que caberia à União, aos Estados e ao Município "favorecer e animar o desenvolvimento das ciências, das artes, das letras e da cultura em geral, proteger os objetos de interesse histórico e o patrimônio artístico do País, bem como prestar assistência ao trabalhador intelectual" (BRASIL, 1934). Além disso, a educação passa a ser vista como um direto de todos e dever da família e do poder público. Porém, as iniciativas de alfabetização dos adultos ainda eram tímidas. Nesse período, as campanhas e movimentos sociais favoráveis à educação de adultos tinham ainda muito mais um caráter assistencialista e não atingiam a grande maioria da população. Na década de 1940, os índices de analfabetismo eram de 56,1\% da população na faixa de 15 anos ou mais (IBGE, SENSO DEMOGRAFICO 1940), muito altos ainda para a época.

Esse alto índice de analfabetismo fez com que, em 1946, após o fim da segunda guerra mundial, fosse desenvolvida a lei Orgânica do ensino primário, o que estabeleceu a modalidade de ensino de supletivo para jovens e adultos. Mas, apenas em 1947, o poder público lança campanhas efetivas para a alfabetização da população, com a criação da Campanha de Educação de Adolescentes e Adultos (CEAA). Houve, na época, uma intensa aceleração do processo de alfabetização e diminuição dos números de analfabetos no país, no entanto, houve inúmeras críticas a essas campanhas devido ao seu caráter superficial e seu desenvolvimento em um curto período, desconsiderando especificidades do ensino para adultos e diversidades regionais. (FERRARO, 2003).

No final da década de 1950, os próprios participantes dessas campanhas de alfabetização se tornaram seus maiores críticos, destacando-se um participante da Campanha Pernambucana que passa a se tornar, em alguns anos, o grande nome da alfabetização de adultos: Paulo Freire. Ele afirmava que a organização e o conteúdo desses cursos de 
alfabetização de jovens e adultos deveriam ter como base a realidade social dos alunos a partir de um trabalho colaborativo e uma estrutura de ensino horizontalizada. Dessa forma, o adulto não alfabetizado não deveria ser visto como alguém inferior e ignorante, como era tratado nas campanhas anteriores, mas sim como um produtor de saberes e culturas.

“ O saber se faz através de uma superação constante. O saber superado já é uma ignorância. $\{\ldots\}$ Portanto, não há saber nem ignorância absoluta: há somente uma relativização do saber ou da ignorância. Por isso, não podemos nos colocar na posição do ser superior que ensina um grupo de ignorantes, mas sim na posição humilde daquele que comunica um saber relativo a outros que possuem outro saber relativo." (FREIRE, 1979, P. 15)

A partir do golpe militar, em 1964, Freire e outros educadores apoiadores de sua proposta sofreram com a repressão do regime; pois, para o governo da época, a alfabetização era uma questão técnica, voltada somente ao ensinamento mecânico, enquanto para esses educadores o ensino para adultos era um processo político pedagógico, apresentando-se como um desenvolvimento cultural de aprendizagem.

Apenas a partir da redemocratização do país, após o fim da ditadura militar, com a constituição de 1988, a educação de adultos foi garantida como um direito, porém o governo não era mais obrigado a garantir esse ensino. Assim, a partir dessa nova realidade, os municípios começam a ampliar as ofertas de educação para jovens e adultos, desenvolvendose tais experiências em espaços não governamentais, como universidades e movimentos sociais.

\section{Nossa experiência que completa 25 anos}

O projeto de alfabetização de jovens e adultos de Botucatu com temas direcionados à saúde surgiu, em 1993, pela iniciativa de alunos da Faculdade de Medicina de Botucatu (FMB) que, ao trabalharem questões de saúde com um grupo de mulheres de um dos bairros mais pobres da cidade, Jardim Peabiru, constataram que a maioria dos participantes do trabalho mal sabia ler e escrever. Ficou evidente, que, por serem analfabetas, as mulheres eram privadas do pleno exercício da cidadania (CARVALHO, 2002). A exclusão da qual sofriam também dificultava o acesso a informações sobre saúde e a incorporação de práticas ao cotidiano relevantes ao controle e à prevenção de doenças. Criou-se, então, o projeto com o objetivo de ampliar a prática da cidadania dos adultos do bairro; suprir a deficiência do aprendizado básico da comunidade; desmistificar e consolidar o conhecimento a respeito dos principais temas de saúde relevantes à realidade da comunidade; incrementar a formação 
humanística dos universitários; bem como sua desenvoltura na obtenção de vínculo com as pessoas da comunidade que utilizam do serviço de saúde (VIEIRA,1998).

As atividades com os alunos alfabetizando são desenvolvidas, até o presente momento, por meio do método de ensino de Paulo Freire e da educação popular em saúde, que aponta que o papel do educador em saúde seria mais o de "ajudar o grupo a pensar do que pensar pelo grupo, mais de questionar do que de discursar, mais de assessorar do que de decidir, contribuindo para seu crescimento em termos de solidariedade, autonomia e consciência" (CARVALHO, 1976). Dessa forma, as atividades, desde o princípio, são desenvolvidas de maneira dialógica, permitindo tanto o aprendizado da linguagem escrita, como a construção de um pensamento crítico pela comunidade. Os alunos do curso médico problematizam situações cotidianas em que são necessárias as habilidades de escrita, leitura e cálculo básico. O material engloba atividades de leitura, interpretação e discussão de textos, retirados de jornais e revistas ou de textos elaborados pelos próprios alunos. Para o aprendizado da matemática, utilizam-se materiais para o apoio didático do aprendizado, como o material dourado e o ábaco. São discutidas nas atividades questões de saúde, sociais, políticas, éticas, econômicas, artísticas e culturais (VIEIRA,1998).

O alfabetizando é o próprio produtor do conhecimento, o que permite resgatar, em si mesmo, os instrumentos para o aprendizado. Assim, esse ambiente proporciona uma relação de troca entre professores/alunos, e procura valorizar o processo de construção de conhecimento pelo coletivo do grupo, apoiando-se em uma concepção ética de respeito ao outro. Convivendo com a dinâmica do processo e interagindo social e culturalmente, o estudante passa a sensibilizar-se com problemas sociais e éticos da população e a aplicar conhecimentos. O alfabetizando aperfeiçoa seu senso crítico, entra em contato com temas e assuntos atuais e é estimulado a refletir e a dialogar sobre o que aprendeu. Adquire autonomia e confiança em si próprio, passando a exercer sua cidadania. A troca de experiências, o diálogo permanente e o comprometimento social permitem aos estudantes refletir sobre obstáculos concernentes à promoção, à prevenção e à educação em saúde na atenção a população adulta (VIEIRA,1998; CYRINO, 1999; CYRINO,2004).

Para a preparação das aulas, inicialmente verificam-se as necessidades educacionais dos alunos participantes. Os graduandos pertencentes à coordenação do projeto desenvolvem atividades, para serem passadas em sala de aula, que estimulam o desenvolvimento dos alunos, visando ao aprendizado: da escrita; da separação de sílabas; da acentuação; do entendimento de palavras e textos; do reconhecimento e escrita correta dos números; no 
aprendizado de operações matemáticas básicas, assim como administrando discussões de textos que trazem essa vivência dialógica de troca entre os envolvidos e que, ao mesmo tempo, auxiliem no processo de aprendizagem. Acreditamos que a integração tanto de textos e discussões com o conteúdo teórico de linguagens e matemática seja uma estratégia mais eficaz para o aprendizado efetivo, a partir da realização de troca de experiências e criação de vínculo com os alunos.

O projeto engloba uma média de 17 alunos anualmente, sendo que em cada aula normalmente estão presentes pelo menos 9 professores para ajudar os alunos e tirar suas dúvidas durante a realização das atividades e contribuindo para as discussões em sala. Dessa forma, esses professores são divididos para ajudar 2 ou 3 alunos, dando-lhes uma atenção especial e direcionada às suas necessidades.

Além disso, realizamos atividades fora da sala de aula com os alunos, que visam tanto à continuidade do aprendizado de uma forma mais lúdica, por meio de passeios anuais a museus e exposições, como a momentos de socialização, por meio de festas, para ampliarmos a proximidade e afinidade dos professores e alunos, permitindo a criação de mais momentos de discussão de troca entre alunos/professores (BRAZ,2018).

Com o passar dos anos, o projeto passa a ter maior visibilidade no campus de Botucatu, ganhando adeptos de cursos além da medicina como o de enfermagem, agronomia, física médica, biomedicina, biologia e outros. Há então uma mobilização comum desses estudantes em prol do projeto e de sua valorização dentro do campus. Atualmente, contamos com um corpo de 95 graduandos participantes do projeto que se revezam para participar das aulas e ajudar os alunos do projeto no desenvolvimento das atividades em aula.

\section{Com a palavra, os protagonistas}

Por meio da fala de nossos protagonistas ${ }^{2}$ trazemos aqui algumas especificidades do presente projeto de extensão universitária. No depoimento de uma das graduandas participantes como professora do projeto, a mesma expressa a sua vivência dele:

Acreditamos que a educação de jovens e adultos é um grande desafio, o adulto como dizemos 'já é um vaso cheio' por mais que não tenha conhecimentos de como escrever letras e palavras, ele já vem com uma história de vida, com experiências,

\footnotetext{
${ }^{2}$ Todos os nomes dos protagonistas foram mantidos no anonimato e foram criados nomes fictícios para os mesmos.
} 
então nunca podemos desconsiderar o seu conhecimento. Em uma atividade que tivemos uma aluna que era empregada doméstica, ela comentou que sempre limpava na biblioteca de onde trabalhava um Globo (terrestre), mas ela não sabia o que eram aqueles desenhos e letras nele. Após uma aula no projeto, ela descobriu que aqueles desenhos que ela tanto imaginava eram países e que lá estava o país que ela morava. Para a maioria das pessoas pode parecer que é pouco, mas dar o significado de uma coisa que antes era apenas mais uma dúvida no cotidiano desses alunos é de grande prazer (Dália, enfermeira).

Nesse relato, é possível observar como o projeto impacta tanto nos alunos como em nós mesmos. Para a maioria de nós, graduandos, com acesso à escolarização desde cedo, reconhecer o globo terrestre é uma tarefa simples e até banal. Porém, para esses alunos sem essa mesma trajetória escolar, o significado dado a esse mesmo objeto é completamente diferente, sendo visto como algo misterioso. Isso mostra como o conhecimento é relativo, dependente muito mais de nossa vivência e, como a falta dessa oportunidade de conhecimento desde a infância, pode impactar na vida das pessoas quando adultas.

Conheci o projeto da Alfabetização de Adultos no início de 2016, a partir de um pôster na faculdade, me interessei muito e resolvi participar. No dia da minha primeira aula, estava ansioso e muito feliz, quando cheguei lá fui surpreendido com a presença de alunos carinhosos e sedentos por conhecimento, foi amor à primeira vista! Criei um carinho enorme pelo projeto que no ano seguinte, 2017, me tornei uns dos coordenadores responsáveis. Foi um ano incrível, posso dizer que um dos melhores que já vivi, a alegria de dar aula às segundas e às quartas-feiras era contagiante, ver o desenvolvimento dos alunos me cativava cada vez mais e mais, são alunos dedicados e muito esforçados, e me sentia na obrigação de ensiná-los pelo menos um pouco do conhecimento que eu possuía, em forma de agradecimento por tudo o que eles me proporcionavam, a alegria e a força para superar meus desafios. Era uma relação de aprendizado mútuo entre nós, e não há sensação melhor do que chegar ao fim do semestre e ver o quanto eles desenvolveram, alunos que antes eram cegos perante ao mundo da escrita se deslumbravam cada vez mais com a independência adquirida pelo fato de conseguirem realizar suas tarefas sozinhos. (Cravo, estudante universitário.)

Neste depoimento, também é possível verificar como nós, professores, criamos, além do vínculo de amizade e proximidade, um vínculo de responsabilidade em relação aos nossos alunos. Nós desejamos ensinar todo o conteúdo de que foram privados em sua vida pela não escolarização, fazendo todo o possível para a compreensão de todos. 
$\mathrm{Na}$ primeira vez a gente vai com aquela ideia de que vai ser professor e que precisa saber varias coisas. Senti um nervosismo porque não achei que ia conseguir, fiquei com medo de mais atrapalhar do que ajudar, mas logo que entrei na sala de aula, todo o meu nervosismo foi embora. Fui recebida com muito carinho, sorrisos esperançosos e que não me cobravam nada mais do que eu já sabia e me passaram a confiança da experiência. Eu vi que não era eu quem estava ensinando, mas sim que nós estávamos aprendendo juntos. É muito gratificante. O projeto de Alfabetização de adultos tem a ver com a troca de experiências, você passa um pouquinho do que você sabe da escola e os alunos passam o que eles aprenderam com a vida. Eu me sinto muito feliz por fazer parte do projeto.(Rosa, estudante universitária)

Analisando a fala de Rosa, verificamos como nós, professores, também aprendemos com a convivência com os alunos. Como somos acostumados desde a infância a um modelo de aula expositivo, em que um professor dá a aula e os alunos apenas escutam, vivenciar esse modelo dialógico de aula é uma experiência nova para muitos de nós, mas que, com o tempo, vemos como é muito mais benéfica e eficaz para o aprendizado dos alunos e do nosso ao mesmo tempo.

Os educandos expressam suas vivências e pensamentos em relação às aulas ministradas. Esses depoimentos foram sugeridos em uma de nossas aulas como uma atividade de desenvolvimento da escrita e a percepção do papel desse encontro.

Eu estou contente com a aulas. Eu adorei a aula de pintura. Quero aprender mais matemática. Tenho dificuldade com as letras e com as palavras com 'Lh'. Eu aprendi a ler e a escrever melhor, minha letra ficou melhor. Quero aprender mais. Eu gosto dos professores. (Camélia, educanda)

Durante o curso, eu aprendi a ler, escrever e a ensinar a minha neta a ler e escrever. A escola me ajudou a tirar a minha carteira de motorista. A escola me ajudou quando eu passei por um momento de dificuldade em minha vida. Aprendi sobre a importância da vacina.”( Primavera, educanda)

Faz um ano que eu estou estudando, mas não aprendi tudo o que eu gostaria ainda. Porém, vou continuar a estudar. Ler um pouquinho mais rápido, aprendi a fazer a tabuada.( Violeta, educanda)

Aprendi a escrever, a leitura, a copiar e a matemática. Falar melhor, comer verdura e leite. Melão, uva, melancia, maçã, banana, laranja .(Jasmin, educanda)

Eu só tenho a agradecer a alfabetização, por vocês terem nos proporcionado um aprendizado de qualidade. Então eu mesma vou terminar o EJA agora, e espero ano 
que vem continuar no projeto. Eu só tenho a agradecer, a alfabetização tem sido muito boa para nós e esperamos voltar sempre.(Margarida, educanda)

Os depoimentos de alguns dos alunos mostram quão diversa é a visão de cada um sobre o projeto. No entanto, todos os alunos apresentam um grande afeto em relação ao projeto e aos professores, mobilizados por este movimento de trabalho com aulas dialógicas que nos permite dar muita importância à visão e ao questionamento de cada um dos alunos durante as aulas. Muitos dos alunos, quando passam por alguma situação difícil em casa ou no trabalho, procuram os estudantes como apoio e que sempre estão abertos a ouvi-los e ajudálos, mantendo com eles uma relação mais profunda de confiança.

\section{Considerações finais}

Os últimos dados do IBGE mostram que no ano de 2017 a taxa de analfabetismo no Brasil era de $7 \%$ da população com 15 anos ou mais de idade, o que corresponde a 11,5 milhões de pessoas, concentradas principalmente na faixa etária dos 60 anos ou mais (IBGE, SENSO DEMOGRAFICO 2017), dados muito altos ainda para a realidade brasileira.

Como visto a partir da análise do histórico do processo de escolarização no Brasil, a educação primária foi por muito tempo relegada ao descaso, sem apresentar muito desenvolvimento e investimentos estatais. Muitos indivíduos ficaram e ainda permanecem isolados dessas escassas tentativas oficiais de alfabetização da população. As tentativas sempre giraram e, em muitos casos ainda hoje, giram em torno de uma ideologia de filantropia, desconsiderando as reais necessidades de conhecimento dessa população, ainda vista como indivíduos "inferiores" e "piores", à margem da sociedade.

Além do mais, verificamos que o fato dessa parcela da população permanecer analfabeta e à margem do processo educacional brasileiro ao longo do tempo faz com que elas não sejam capazes de exercer por completo a sua cidadania, por não permitir a essa população o acesso à leitura e a consciência de seus direitos.

A proposta aqui apresentada, baseada na teoria de Paulo Freire, visa romper com modelos colonizadores que fizeram e ainda fazem essa população se manter à margem do processo de escolarização e do exercício de sua cidadania. Para isso, nosso objetivo no projeto é sempre manter um ambiente de troca entre professores/alunos, valorizando os pensamentos e vivências dos participantes e levando para eles os conhecimentos teóricos necessários para a sua completa inserção na sociedade atual. 
Além disso, essa vivência do projeto permite a nós, graduandos, muito mais do que aprender a guiar as discussões ou ensinar a linguagem escrita, leva-nos a viver uma intensa troca de experiências e a olhar o outro de uma forma muito mais profunda, o que faz dessa vivência um grande aprendizado para a nossa formação pessoal e profissional.

\section{REFERÊNCIAS:}

BRASIL, Constituição Política do Império do Brazil, de 25 de março de 1824.

BRASIL, Constituição dos Estados Unidos do Brasil, de 24 de fevereiro de 1891.

BRASIL. Constituição da República Federativa do Brasil de 1934. Institui a Constituição Federal do Brasil. Brasília, 1934

BRAZ, N. S. ; VALADAO, S. S. ; SELIGER, B. P. A. ; AMANCIO, S. C. P. ; CYRINO, E.G. PROBLEMATIZAR PARA EDUCAR: 25 ANOS DO PROJETO ALFABETIZAÇÃO DE JOVENS E ADULTOS. In: $13^{\circ}$ Congresso Internacional Rede Unida, 2018, Manaus. Revista Saúde em Redes Suplemento, Anais do $13^{\text {a }}$ Congresso Internacional da Rede UNIDA. Porto Alegre: Rede Unida, 2018. v. 4. p. 1890-1890.

CARNEIRO LEÃO, A. C. A sociedade rural: seus problemas e sua educação. Rio de Janeiro: A Noite, 1939

CARVALHO, A.I. Saúde e educação de base: algumas notas. p.28-33.(mimeo), 1976.

CARVALHO, José Murilo de. Cidadania no Brasil. O longo caminho. 3 ed. Rio de Janeira: Civilização Brasileira, 2002.

CYRINO, E.G. Projeto de Alfabetização de Adulto por meio da Educação em Saúde. In: I Congresso de Extensão Universitária da Unesp, 1999, São Pedro. Resumo, 1999. p. 279-280.

CYRINO,E.G.; FREITAS, Viviane . Programa de Alfabetização tem destaque nacional. Boletim Informativo - Faculdade de Medicina, Botucatu, p. 3 - 3, 03 set. 2004.

GALVÃO, Ana Maria de Oliveira; SOARES, Leôncio José Gomes. História da alfabetização de adultos no Brasil. In: ALBUQUERQUE, E.B.; LEAL, T.F. A alfabetização de jovens e adultos: em uma perspectiva de letramento. Belo Horizonte: Autêntica, 2004.

FERRARO, A. R. História quantitativa da alfabetização no Brasil. In: RIBEIRO, V. M. (Org.). Letramento no Brasil. São Paulo: Global, 2003.

FERRARO, Alceu Ravanello. História inacabada do analfabetismo no Brasil. São Paulo: Cortez Editora, 2009.

FREIRE, Paulo. Educação e Mudança. 12a Edição. Paz e Terra. Rio de Janeiro, 1979. 


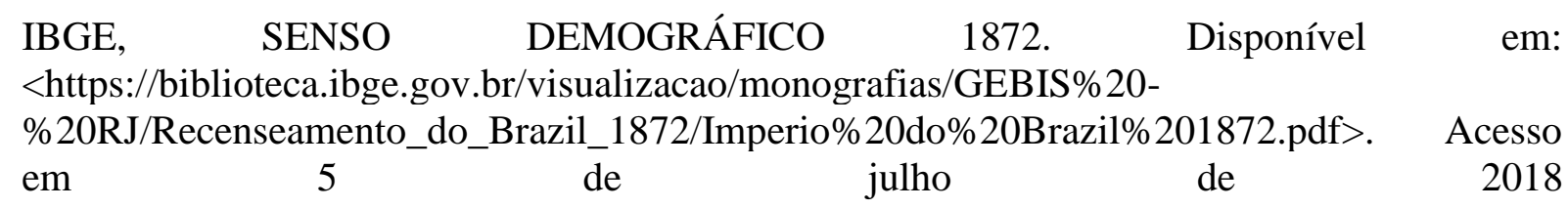

IBGE, SENSO DEMOGRÁFICO $1940 . \quad$ Disponível em: <https://biblioteca.ibge.gov.br/visualizacao/periodicos/65/cd_1940_v2_br.pdf>. Acesso em 2 de julho de 2018

IBGE, SENSO DEMOGRÁFICO $2017 . \quad$ Disponível em: <https://agenciadenoticias.ibge.gov.br/agencia-noticias/2012-agencia-denoticias/noticias/21255-analfabetismo-cai-em-2017-mas-segue-acima-da-meta-para2015.html>. Acesso em 27 de junho de 2018

VIEIRA, F. L. ; GOLDFARB CYRINO, E. ; ANTONISSEN, K. ; ASSALIM, V. ; SILVA, A. ; YOSHIDA, V. ; PEREIRA, M. L. . Outras leituras da realidade: alfabetização de adultos pela educação em saúde. Interface (Botucatu. Impresso), Botucatu, v. 2, n.2, p. 221-224, 1998. 